\title{
Original
}

\section{Enhancement of the Delayed-Type Hypersensitivity to Trinitrochlorobenzene in Hypophysectomized Mice}

\author{
Michiko AmemiYa, Yuji KiUchi, Tatsutaka Yamamoto*, \\ Takako KaSAHARA*, Tadashi Hisamitsu* \\ and Katsuji OGUCHI
}

\begin{abstract}
The aim of the present study was to investigate the role of the pituitary in the delayed-type hypersensitivity (DTH) response in mice. We examined the effect of hypophysectomy on 2,4,6-trinitrochlorobenzene (TNCB)induced DTH, which has been used as a cellular immunity model in vivo. Seven-week-old male BALB/c and C57BL/6 mice were used. Six days after sensitization with TNCB, TNCB was applied to the left ear pinnea and the DTH response was measured as the degree of ear swelling 24 hours after TNCB challenge. The TNCB-DTH reaction was also measured 24 hours after intracisternal injection of $\alpha$-helical coricotropin-releasing factor (CRF), a CRF inhibitor, at doses of $0.4,1,5$, and $10 \mu \mathrm{g}$. Maximal ear swelling in both hypophysectomized mice and mice that received $\alpha$-helical CRF was significantly increased. Histologically, adrenocortical atrophy and deposition of lipid were observed in hypophysectomized mice at the time DTH was enhanced. These results suggest that pituitary ACTH plays a suppressive role in the DTH response in mice.
\end{abstract}

Key words: delayed-type hypersensitivity, cellular immunity, hypophysectomized mice, ACTH

\section{Introduction}

Several studies have found evidence for hormonal regulation of immune reactions. The immunosuppressive effect of adrenal glucocorticoids is well established ${ }^{1-5)}$. On the other hand, pituitary hormones have been shown to have an important role in the maintenance of immunocompetence ${ }^{6-11)}$. We previously reported that a single electroacupuncture treatment in mice suppressed the ear swelling induced by delayed-type hypersensitivity (DTH), cellmediated immunity ${ }^{12)}$. In addition, a single electroacupuncture treatment in hypophysectomized mice did not suppress the ear swelling induced by $\mathrm{DTH}^{13)}$. These findings suggest that pituitary hormones have a regulatory role in the DTH response. In particular, pituitary ACTH is thought to have a regulatory role in immune responses ${ }^{14)}$. Therefore, in the present study, to elucidate the role of pituitary hormones in the DTH response in mice, the effects of hypophysectomy on 2,4,6-trinitrochlorobenzene (TNCB)-induced DTH and DTH reaction after intracisternal injection of $\alpha$-helical corticotropin-releasing factor (CRF) were investigated.

Department of Pharmacology, Showa University School of Medicine, 1-5-8 Hatanodai, Shinagawa-ku, Tokyo 142, Japan.

* Department of Physiology, Showa University School of Medicine. 


\section{Materials and Methods}

Mice

Seven-week-old male BALB-c and C57BL/6 mice were purchased from Nihon SLC Co., Ltd. (Hamamatsu, Japan). Mice were kept in plastic cages with food and water given ad libitum in a temperature-controlled room $\left(23 \pm 1^{\circ} \mathrm{C}\right)$ with a 12-hour light:dark cycle $(6: 00 \sim$ 18:00 hours). Hypophysectomy (audiomeatal method) and sham operations were performed 1 or 2 weeks before sensitization.

TNCB sensitization and challenge for induction of DTH

DTH sensitization and challenge were conducted as described previously ${ }^{12)}$. Briefly, mice were sensitized by application of $100 \mu \mathrm{l}$ of 7\% TNCB (Tokyo Kasei Kogyo Co., Ltd., Tokyo, Japan) in ethanol on shaved abdominal skin 6 or 13 days before challenge. On the day of the challenge experiment (day 0 ), $30 \mu \mathrm{l}$ of $1 \%$ TNCB in olive oil was applied to the left ear pinnea. Maximal ear swelling was evaluated 24 hours after TNCB was applied to the ear. The thickness of ears was measured to the nearest $0.01 \mathrm{~mm}$ with a dial thickness gauge (Peacock G, Ozaki Co., Ltd., Tokyo, Japan) under sodium pentobarbital anesthesia (Abbot Laboratories, N. Chicago, Il., U.S.A.) the thickness before challenge was subtracted from that after challenge. Ears were measured without knowledge of animal treatments.

Intracisternal injection of $\alpha$-helical $C R F$

$\alpha$-Helical CRF in saline was injected intracisternally at doses of $0.4,1,5$, and $10 \mu \mathrm{g}$ in $10 \mu \mathrm{l}, 15$ minutes before TNCB challenge. An equal volume of saline was injected to control mice. Intracisternal injection was done with a 500- $\mu$ l syringe with a J-shaped 29-gauge needle, curved $\left(40^{\circ}\right) 3.5 \mathrm{~mm}$ from the tip. The conscious mouse was held in a mouse holder (KN-330, Natsume Seisakusho Co., Ltd., Tokyo, Japan). The tip of the needle was inserted into the cleft between the occiput and the atlas. A 10- $\mu$ l aqueous solution was injected slowly into the cisterna magna and the needle was withdrawn ${ }^{15)}$. To confirm that the injection sites were in the cisterna magna, $0.4 \%$ trypan blue was injected into the same site.

Histologic examination

The adrenal glands were removed 24 hours after TNCB challenge in control and hypophysectomized (2 weeks after operation) BALB/c mice and fixed in $10 \%$ formalin. The adrenal gland was stained with hematoxylin and eosin or oil-red-o.

Statistical analysis

Ear thicknesses are expressed as mean \pm SD. Statistical analysis was performed with the unpaired Student's $t$-test. Differences with $\mathrm{p}<0.05$ were considered significant.

\section{Results}

\section{Effect of HPX on the DTH induced by TNCB}

Maximal ear swelling 24 hours after TNCB challenge in hypophysectomized BALB/c mice sensitized 1 week after operation $\left(31.9 \pm 3.4 \times 10^{-3} \mathrm{~cm}\right)$ was significantly greater $(140 \%)$ than in sham-operated mice (Fig. 1A). The difference in swelling between sham-operated mice and untreated control mice was not significant (data not shown). Maximal ear swelling in hypophysectomized BALB/c mice sensitized 2 weeks after operation $(32.5 \pm 2.2 \times$ $10^{-3} \mathrm{~cm}$ ) was significantly greater than that in either sham-operated $(256 \%)$ or control $(160 \%)$ mice. The swelling in sham-operated mice was significantly less than in control mice (Fig. 1B). On the other hand, the maximum ear swelling in hypophysectomized 
(A)

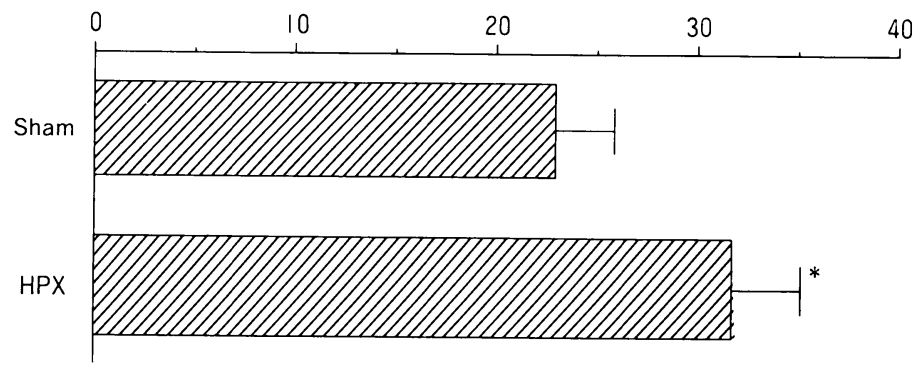

(B) Ear swelling $\left(\times 10^{-3} \mathrm{~cm}\right)$

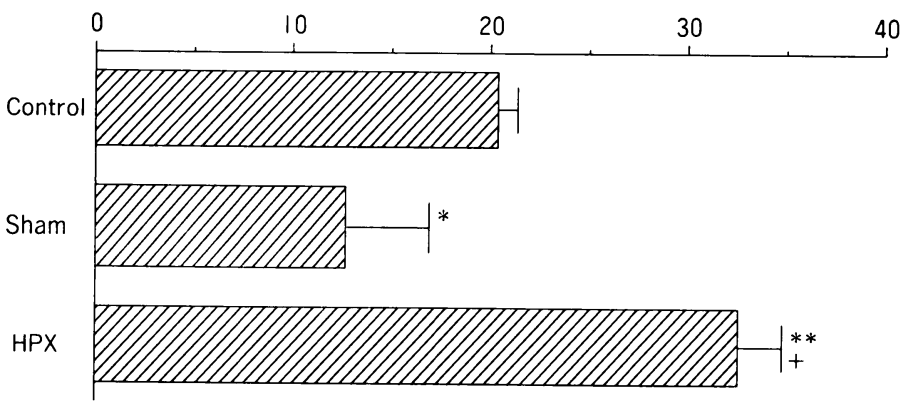

(C) Ear swelling $\left(\times 10^{-3} \mathrm{~cm}\right)$

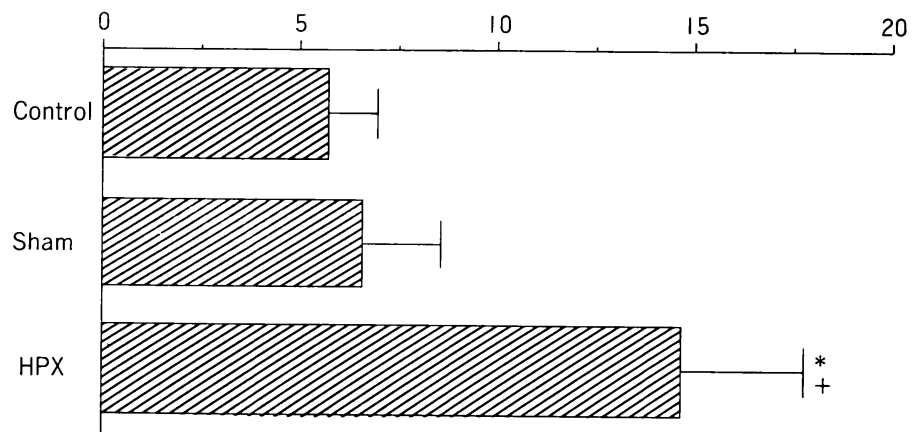

Fig. 1. Effect of hypophysectomy (HPX) on the DTH induced by TNCB in BALB/c and C57BL/ 6 mice. Sensitization was performed 6 days before challenge. Ear swelling 24 hours after TNCB challenge was measured. BALB/c mice were sensitized 1 week (A) or 2 weeks (B) after operation and (C) C57BL/6 mice were sensitized 2 weeks after operation. Each column shows mean $\pm \mathrm{SD}$ for 3 to 6 mice. $* \mathrm{p}<0.01$, ${ }^{* *} \mathrm{p}<0.001$ vs control, ${ }^{+} \mathrm{p}<0.01$ vs sham (Student's $t$-test). 


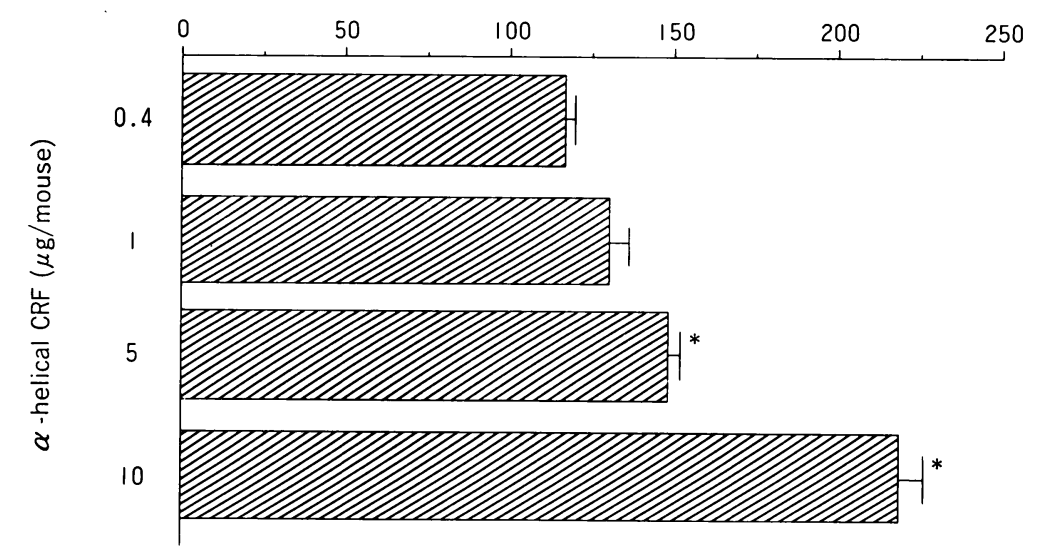

Fig. 2. Effect of intracisternally injected $\alpha$-helical CRF on the DTH induced by TNCB in BALB/c mice. Sensitization was performed 6 days before challenge. $\alpha$-Helical CRF was injected intracisternally 15 minutes before TNCB challenge. Ear swelling 24 hours after challenge was measured. The results are expressed as percentages of that in a saline-injected control group. Each column shows mean \pm SD for 6 to 7 mice. ${ }^{*} \mathrm{p}<0.01$ vs control (Student's $t$-test).

C57BL/6 mice was $14.5 \pm 3.1 \times 10^{-3} \mathrm{~cm}$. The DTH response was significantly greater in hypophysectomized mice than in either control $(249 \%)$ or sham-operated $(219 \%)$ mice (Fig. 1C).

Macroscopically, none of the hypophysectomized mice was found to have residual pituitary tissues at autopsy after the experiments.

Effect of intracisternally injected $\alpha$-helical CRF on the DTH induced by TNCB

The swellings in mice pretreated with $\alpha$-helical CRF at doses of $0.4,1,5$, and $10 \mu \mathrm{g}$ was $13.9 \pm 2.7,25.6 \pm 5.8,29.3 \pm 3.9$, and $22.3 \pm 6.8 \times 10^{-3} \mathrm{~cm}$, respectively, which were $118 \%$, $131 \%, 148 \%$, and $219 \%$ of that in the control group (Fig. 2). Thus, $\alpha$-helical CRF increased the ear swelling at 24 hours after TNCB challenge in a dose-dependent manner.

Histologic change in the adrenal gland of hypophysectomized mice

Adrenal glands in hypophysectomized and control BALB/c mice were compared histologically. In hypophysectomized mice, the adrenal cortex, mainly the zona fasciculate and the zona reticularis, was atrophic (Fig. 3B) and more intensely stained with oil-red-o than in control mice (Fig. 3D).

\section{Discussion}

DTH is a T-cell-dependent inflammatory reaction that has been frequently used as an animal model for the study of cellular immunity. We previously reported that electroacupuncture-induced DTH suppression was inhibited in hypophysectomized mice ${ }^{12,13)}$. Thus, in the present study, we used this model to investigate possible involvement of pituitary gland hormones, especially ACTH, in the immune system.

We found significantly greater DTH reactions in hypophysectomized BALB/c and C57BL/ 6 mice, suggesting that functional cell-mediated immune responses are commonly regulated 


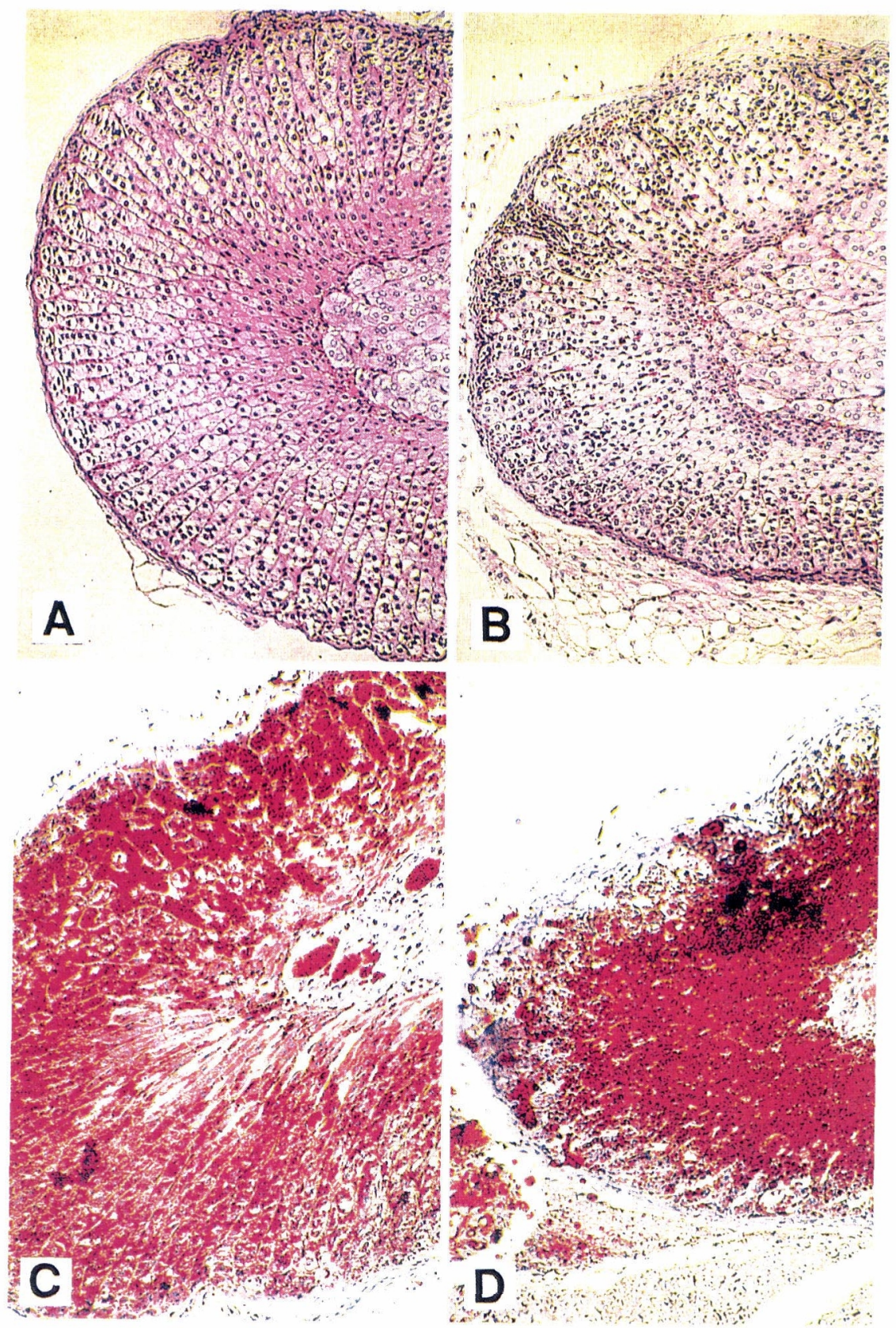

Fig. 3. Histologic change of adrenal gland in hypophysectomized (HPX) BALB/c mice. Adrenal glands in control and HPX mice were obtained 24 hours after TNCB challenge. A, Control; B, HPX; hematoxylin and eosin stain, $\times 100$. C, Control; D, HPX; oil-red-o stain, $\times 100$. 
or modulated by pituitary hormones in both strains. The DTH reaction in BALB/c mice sensitized 2 weeks after operation was more enhanced than that in mice sensitized 1 week after operation. Furthermore, pretreatment with $\alpha$-helical CRF, a CRF inhibitor, was shown to increase ear swelling 24 hours after TNCB challenge in a dose-dependent manner. This result suggests that ACTH might suppress cell-mediated immune responses in mice.

Since glucocorticoids are immunosuppressive, the increased DTH reaction in hypophysectomized mice might have resulted from adrenal atrophy. Indeed, in the present study, adrenocortical atrophy and deposition of lipid were observed in hypophysectomized mice sensitized 2 weeks after the operation by which DTH was enhanced. However, in hypophysectomized rats, while adrenocortical atrophy and deposition of lipid are also observed, cell-mediated immune responses are decreased ${ }^{11,16,17}$. These findings suggest that enhancement of DTH in hypophysectomized mice might not result from adrenocortical dysfunction. Namely, this effect is probably not produced by impairment of the hypothalamic-pituitary-adrenocortical axis. In fact, there are several neurochemical or behavioral reports of actions of ACTH other than those on this axis. It has been demonstrated that dopaminergic transmission between the anterior and posterior parts of the hypothalamic arcuate nucleus is accelerated by presynaptic action of ACTH released from the pituitary gland ${ }^{18,19)}$.

Pituitary ACTH has direct effects on immune responses. Blalock et al. ${ }^{14}$ ) suggest that ACTH acts as a signal transmitter among cells of the immune system or between the immune system and other organs or both. Another report ${ }^{20)}$ states that immune cells are closely associated with the brain and suggests that an afferent information mechanism exists between immune cells and the brain. However, the precise mechanism involved in ACTHrelated regulation of DTH observed in this study is not clear.

In the present study, DTH was increased by hypophysectomy or intracisternal injection of $\alpha$-helical CRF, suggesting that pituitary ACTH plays a suppressive role in DTH in mice. This effect might result from the disappearance of direct stimulation by ACTH on the central nervous system rather than an indirect effect via the adrenal gland. However, further studies on the mechanism of the possible suppressive effect of ACTH on DTH are expected.

\section{References}

1) Amerose CT: The requirement for hydrocortisone in antibody-forming tissue cultivated in serumfree medium. J Exp Med, 119: 1027-1041 (1964)

2) Cohen JR, Stavy L and Feldman M: Glucocorticoids and cellular immunity in vitro. J Exp Med, 132: 1055-1070 (1970)

3) Sherman NA, Smith RS and Middleton E Jr: Effect of adrenergic compounds, aminophylline and hydrocortisone, on in vitro immunoglobulin synthesis by normal human peripheral lymphocytes. $J$ Allergy Clin Immunol, 52: 13-22 (1973)

4) Stein $M$ and Shiavi RC: Influence of brain and behavior on the immune system. Science, 191: 435-440 (1976)

5) Lauerma AI, Rasanen $L$, Reunala $T$ and Reitamo S: Langerhans cells but not monocytes are capable of antigen presentation in vitro in corticosteroid contact hypersensitivity. $\mathrm{Br} J$ Dermatol, 123: 699705 (1990)

6) Duquesnoy RJ, Marinai T and Good RA: Effect of hypophysectomy on immunological recovery after sublethal irradiation of adult rats. Proc Soc Exp Biol Med, 131: 1176-1178 (1969)

7) Fabris N, Pierpaoli $W$ and Sorkin E: Hormones and the immunological capacity. The immunodeficiency disease of the hypopituitary Snell-Bagg dwarf mouse. Clin Exp Immunol, 9: 209-225 (1971)

8) Fabris N, Pierpaoli W and Sorkin E: Hormones and the immunological capacity. Restorative effects 
of developmental hormones or of lymphocytes on the immunodeficiency syndrome of the dwarf mouse. Clin Exp Immunol, 9: 227-240 (1971)

9) Fabris N, Pierpaoli W and Sorkin E: Lymphocytes, hormones and ageing. Nature, 240: 557-559 (1972)

10) Pierpaoli W and Sorkin E: A thymus-dependent function of the adrenal cortex and its relation to immunity. Experientia, 29: 851-852 (1972)

11) Exon JH, Bussiere JL and Williams JR: Hypophysectomy and growth hormone replacement effects on multiple immune responses in rats. Brain Behav Immun, 4: 118-128 (1990)

12) Kasahara T, Wu Y, Sakurai $Y$ and Oguchi K: Suppressive effect of acupuncture on delayed-type hypersensitivity to trinitrochlorobenzene and involvement of opiate receptors. Int J Immunopharmacol, 14: 661-665 (1992)

13) Kasahara T, Amemiya $\mathrm{M}, \mathrm{Wu} \mathrm{Y}$ and Oguchi $\mathrm{K}$ : Involvement of central opioidergic and nonopioidergic neuroendocrine systems in the suppressive effect of acupuncture on delayed-type hypersensitivity in mice. Int J Immunopharmacol, 15: 501-508 (1993)

14) Blalock JE, Harbour-McMenamin E and Smith EM: Peptide hormones shared by the neuroendocrine and immunologic systems. J Immunol, 135: 858S-861S (1985)

15) Ueda $\mathrm{H}$, Amano $\mathrm{H}$, Shiomi $\mathrm{H}$ and Takagi $\mathrm{H}$ : Comparison of the analgesic effects of various opioid peptides by a newly devised intracisternal injection technique in conscious mice. Eur J Pharmacol, 56: 265-268 (1979)

16) Nagy E and Berczi I: Immunodeficiency in hypophysectomized rats. Acta Endocrinol, 89: 530-537 (1978)

17) Nagy E, Berczi I and Sabbadini E: Endocrine control of the immunosuppressive activity of the submandibular gland. Brain Behav Immun, 6: 418-428 (1992)

18) Tsuchiya $M$ and Takeshige C: Presynaptic actions of $\beta$-endorphin and ACTH on dopaminergic synaptic transmission in the arcuate nucleus for production of acupuncture and nonacupuncture point stimulation-produced analgesia. J Showa Med Assoc, 50: 115-122 (1990) (in Japanese)

19) Zhao WH, Guo SY and Takeshige C: Relations between pituitary gland and neuronal activity in the posterior hypothalamic arcuate nucleus in production of analgesia by nonacupuncture point stimulation. J Showa Med Assoc, 50: 622-628 (1990) (in Japanese)

20) Besedovsky HO, Del Rey AE and Sorkin E: Immunoneuroendocrine interactions. J Immunol, 135: 750S-753S (1985)

[Received March 27, 1996: Accepted April 11, 1996] 